\title{
Novel radio-chromic solution dosimeter for radiotherapy treatment planning
}

\author{
Khalid A. Rabaeh a,b, Akram A. Moussa ${ }^{\text {c }}$, Ahmed A. Basfar ${ }^{\text {a,* }}$, \\ Rashed I. Msalam ${ }^{\text {a }}$
}

\author{
${ }^{a}$ Radiation Technology Center, Atomic Energy Research Institute, King Abdulaziz City for Science \\ and Technology, Riyadh, KSA 11442, Saudi Arabia \\ ${ }^{\mathrm{b}}$ Medical Imaging Department, Faculty of Allied Health Sciences, Hashemite University, Zarqa, Jordan \\ ' Biomedical Physics Department, Research Center, King Faisal Specialist Hospital and Research Center, \\ Riyadh, KSA, Saudi Arabia
}

Received 5 December 2011; received in revised form 16 May 2012; accepted 18 May 2012 Available online 15 June 2012

\section{KEYWORDS \\ Dosimetry; \\ Radio-chromic \\ solution; \\ Nitro blue \\ tetrazolium; \\ Sodium formate; \\ Absorbance}

\begin{abstract}
Nitro blue tetrazolium (NBT) solution dosimeters were prepared and investigated based on radiation-induced reduction of $\mathrm{NBT}^{2+}$. NBT solution dosimeters containing different concentrations of NBT dye from 1 to $5 \mathrm{mM}$ were prepared in a solution of ethanol. The dosimeters were irradiated with $6 \mathrm{MV}$ X-ray beam at doses up to $30 \mathrm{~Gy}$. The dose sensitivity of NBT solution increases strongly with increase of concentrations of NBT dye. The dose response of NBT dosimeters increases remarkably by addition of various concentrations of sodium formate $(0.5,2.5$ and $5 \mathrm{mM})$. It becomes more remarkable with increasing $\mathrm{pH}$ value of NBT-sodium formate dosimeters. The sensitivity of the solution increased fairly with increase of irradiation temperature, therefore, the response of the solutions has to be corrected under actual processing conditions. The stability of solution dosimeters after irradiation was very high up to 30 days.

(c) 2012 Associazione Italiana di Fisica Medica. Published by Elsevier Ltd. All rights reserved.
\end{abstract}

\section{Introduction}

Treatment of cancer by radiotherapy has increased and developed greatly, therefore quality control of dosimetric techniques in medical applications are needed for providing accurate evaluation of doses absorbed in tumor volume and adjacent tissues. Radio-chromic dosimeters (material that turns color due to a radiation-induced chemical changes) have a long history in the field of ionizing radiation dosimetry [16]. Fricke-gelatin-xylenol orange mixture is known as the FGX gel dosimeter can be measured spectrophotometrically $[9,10]$. FGX gel dosimeter demonstrated

\footnotetext{
* Corresponding author.

E-mail address: abasfar@kacst.edu.sa (A.A. Basfar).
} 
reproducible linear dose response up to 25 Gy for radiotherapy treatment planing [6]. It was found that the most important factors that affect the response of FGX gel dosimeter are diffusion of ferric ions which result in an increase in the concentration of the $\mathrm{XO}-\mathrm{Fe}^{3+}$ complex and therefore a change in the optical absorbance of the FGX gel dosimeter.

A dosimeter similar to the present solution based on tetrazolium salt dyes for high dose application such as sterilization and food irradiation was developed [11]. Tetrazolium salts have long been known as quaternary ammonium compounds with a significant property of forming water insoluble, highly colored formazans by reduction [3]. The reduction/oxidation reactions in tetrazolium salts and the change in their colors by forming formazans can also take place using ionizing radiation $[4,13]$. A considerable increase in dose response of NBT-PVA film dosimeters [14] and NBT gel dosimeters [1] was observed by adding appropriate concentration of sodium format and Triton X-100. Different concentrations of 2,3,5triphenyltetrazolium chloride (TTC) in aqueous solution were investigated [12]. It was found that a linear response of absorbance increase with dose over the dose range 1-16 kGy. On the other hand, nitro blue tetrazolium (NBT) solution dosimeters were investigated [11]. It was found that NBT dosimeters could be used over the dose range of 100-1000 Gy. Recently, aqueous and aqueous-alcoholic solutions containing different concentrations of tetrazolium violet (TV) was measured in the dose range of $250 \mathrm{~Gy}$ up to $75 \mathrm{kGy}$ [7]. Appleby [1] introduced a three dimensional imaging of the high dose $(700 \mathrm{~Gy})$ distributions of the radiated tetrazolium (NBT) gel dosimeters via optical scanning techniques. In fact, so far the use of tetrazolium solution dosimeters for low doses has not been reported. Therefore, the present work introduces nitro blue tetrazolium (NBT) solution as single point radio-chromic solution dosimeters that have a potential use in medical dosimetry for radiotherapy treatment planning over the dose range of 2.5-30 Gy.

\section{Experimental}

The nitro blue tetrazolium chloride, $\mathrm{NBTCl}_{2} \quad\left(\mathrm{C}_{40} \mathrm{H}_{30}\right.$ $\mathrm{Cl}_{2} \mathrm{~N}_{10} \mathrm{O}_{6} \cdot \mathrm{H}_{2} \mathrm{O} . \mathrm{CH}_{4} \mathrm{O} ; \mathrm{MW} 867.70$ ) was used as received from (Biosynth, USA). Sodium formate $\left(\mathrm{CHNaO}_{2} ; \mathrm{M} \mathrm{W}: 68\right)$ was used as received from (EMD Chemicals, USA), and $96 \%$ ethanol from Merck was used as received as a solvent for the previous chemicals. The solutions were kept in $3 \mathrm{ml}$ sealed glass ampoules and stored in the dark at room temperature $(23 \pm 1)$. The $\mathrm{pH}$ of the solutions was set with $\mathrm{HCl}$ and $\mathrm{NaOH}$, respectively.

Five hours before irradiation, all solution dosimeters were transferred to the temperature controlled radiation source room to reach equilibrium conditions. The irradiation was carried out using the $18 \mathrm{MV}$ X-ray beam (Varian Medical Systems Inc.) with the maximum dose rate of $300 \mathrm{cGy} \mathrm{min}^{-1}$. Each dosimeter ampoule was placed in a polystyrene holder in a water-phantom acrylic tank. The samples were irradiated with different doses at $15 \mathrm{~cm}$ depth, $100 \mathrm{~cm}$ (SSD) set-up and $10 \times 10 \mathrm{~cm}^{2}$ field size. The samples were transferred back to the refrigerator and kept for about $24 \mathrm{~h}$ before optical measurement.
UV/VIS spectrophotometer is used to measure the absorbance of spectra of radiation in the near infrared $(700-1100 \mathrm{~nm})$, visible $(350-700 \mathrm{~nm})$ and ultra violet $(190-350) \mathrm{nm}$ regions. The absorption spectra of irradiated NBT solutions in the wavelength range from 350 to $650 \mathrm{~nm}$ were measured using UV/VIS spectrophotometer, model Lambda 850, from Perkin-Elmer, USA. Three samples at each absorbed dose were measured and the average is reported. In general, evaluation of NBT solution dosimeres followed ASTM standard guide for performance characterization of dosimeters and dosimetry systems for use in radiation processing, ASTM E2701-09 (ASTM Standard Guide E2701-09).

\section{Results and discussion}

\section{Effect of dye concentration}

Variable concentrations of NBT $(\mathrm{pH}=5.6)$ dye ranging from 1 to $5 \mathrm{mM}$ were used to investigate the effect of the dye concentrations on the response of the NBT dosimeters. The absorption spectra of un-irradiated as well as irradiated NBT solutions were recorded in the range of $450-650 \mathrm{~nm}$. Figure 1 demonstrates the absorbance of $5 \mathrm{mM}$ of NBT $(\mathrm{pH}=5.6)$ in the dose range of $0-30 \mathrm{~Gy}$. The absorption maximum is located at about $521 \mathrm{~nm}$ with a shoulder at about $572 \mathrm{~nm}$ due to the absorbance of the mono-formazan that forms with an initial G-value of 3 molecule/100 eV [11]. It was observed that the absorbance on the long wavelength side of the spectrum gets stronger with the increasing absorbed dose, as a result of formation of diformazan species from reduction of mono-formazan species.

The dose response curves were established in terms of change in absorbance measured at the absorption peak, $521 \mathrm{~nm}, \Delta A\left(\Delta A=A_{x}-A_{0}\right)$ versus the absorbed dose, where $A_{x}$ and $A_{0}$ are absorbance values at $521 \mathrm{~nm}$ for irradiated and unirradiated solutions. The dose response curves of the NBT solutions are shown in Fig. 2.

Dose response of NBT solutions increases significantly with increasing absorbed dose, which can be seen from the increase of the individual relative absorbance-dose curve

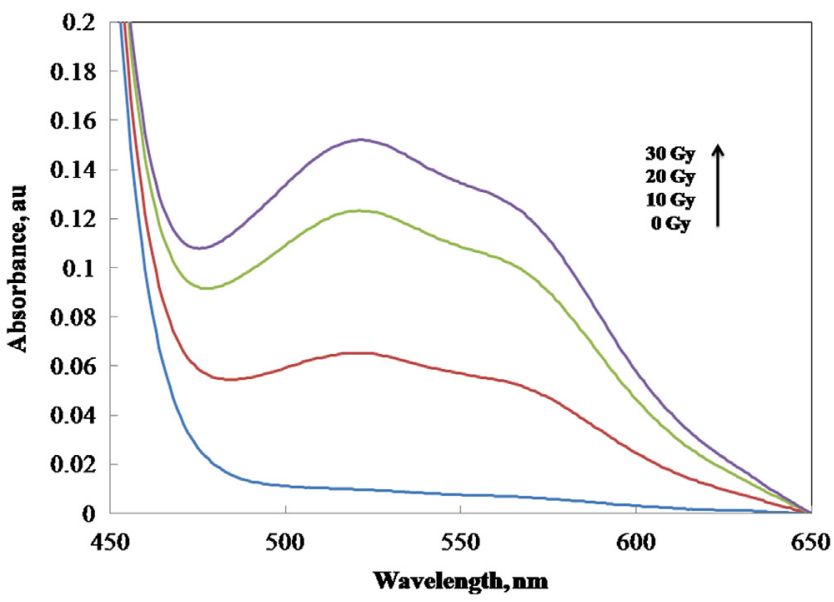

Figure 1 Absorbance of $5 \mathrm{mM}$ of NBT solution dosimeters as a function of wavelength for various absorbed doses. 


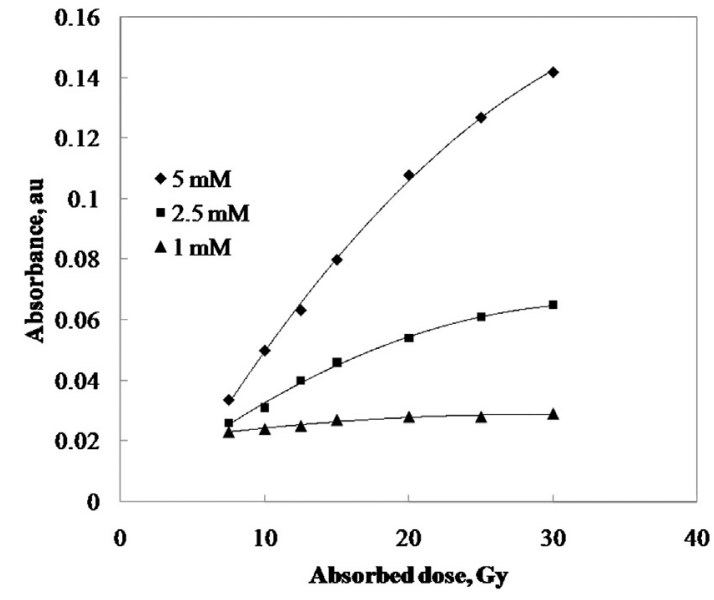

Figure 2 Absorbance at $521 \mathrm{~nm}$ of $1,2.5$, and $5 \mathrm{mM} \mathrm{NBT}$ solution dosimeters as a function of absorbed dose.

(see Fig. 2, for example the absorbance of linear portion (7.5-15 Gy) of $5 \mathrm{mM}$ curve increases $0.046 \mathrm{a} . \mathrm{u}$ for each absorbed dose unit). As the dose increases, more hydrated electrons and free radicals are generated leading to the breakage of $\mathrm{N}-\mathrm{N}^{+}$bonds of NBT, resulting in an increase in the formation of formazan. The results show that dose response increases with increase of dye concentration (see Fig. 2, for example, the sensitivity of linear portion (7.5-15 Gy) for $5 \mathrm{mM}$ curve equals 2.3 the sensitivity of linear portion (7.5-15 Gy) for $2.5 \mathrm{mM}$ curve) due to the higher probability of interaction of the reductive radiolysis products with a greater number of solute molecules, indicating that NBT dosimeter solutions containing higher concentrations of the NBT dye are more suitable for verification of radiotherapy treatment planning. This observation is in a good agreement with previous work by [7].

\section{Effect of additives}

The effect of sodium formate was investigated by preparing three types of solution dosimeters containing $5 \mathrm{mM} \mathrm{NBT}$

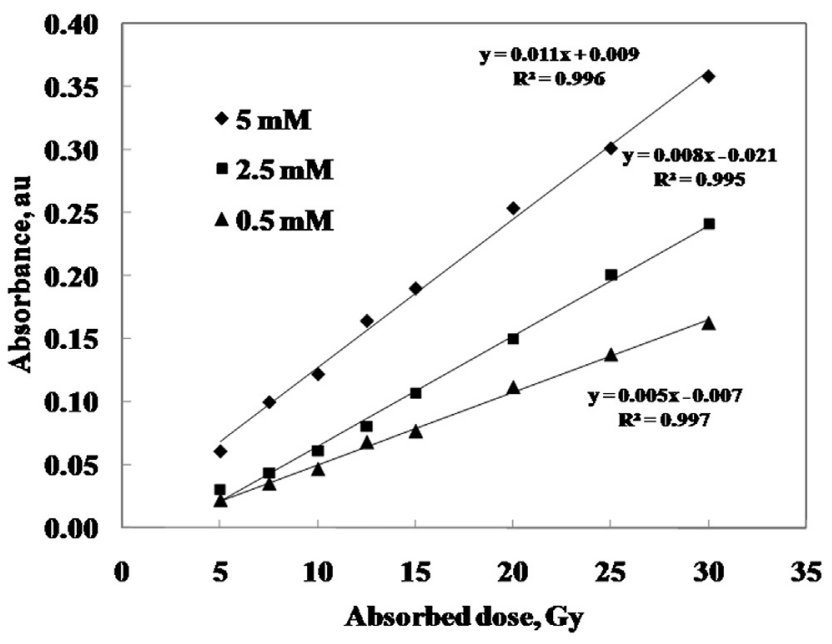

Figure 3 Absorbance of $5 \mathrm{mM} \mathrm{NBT}$ solution dosimeters with various concentrations of sodium formate as a function of dose. with variable concentrations of sodium formate $(0.5,2.5$ and $5 \mathrm{mM}$ ). Figure 3 shows response to gamma radiation of irradiated solutions containing $5 \mathrm{mM}$ NBT with variable concentrations of sodium formate in terms of absorbance at $521 \mathrm{~nm}$ against absorbed dose. The results show that the gamma radiation sensitivity increases linearly with increasing absorbed dose up to $30 \mathrm{~Gy}$ and it increases from 0.0058 to $0.0115 \mathrm{~Gy}^{-1}$ ) with increase of sodium formate concentrations from 1 to $5 \mathrm{mM}$, due to some of the radicals formed from sodium formate which play a role in promoting reduction of NBT [17]. This result is in a good agreement with previous study by [1].

\section{Effect of $\mathrm{pH}$}

The effect of $\mathrm{pH}$ on the radiation induced reduction of NBT dye was investigated by irradiating solution samples containing $5 \mathrm{mM} \mathrm{NBT}$ and $5 \mathrm{mM}$ sodium formate with different $\mathrm{pH}$ values in the range 5.6-9 at irradiation temperature of $20 \pm 1{ }^{\circ} \mathrm{C}$. The $\mathrm{pH}$ of the solutions was set with $\mathrm{HCl}$ and $\mathrm{NaOH}$, respectively. The optical absorbance of irradiated alkaline solutions has higher values compared to irradiated neutral solutions (see Fig. 4) due to the change of the extinction coefficient of the monoformazan [11]. Similar findings were observed recently $[7,15]$.

\section{Effect of irradiation temperature}

The effect of irradiation temperature on the response of NBT solution dosimeters was investigated by irradiating samples containing $5 \mathrm{mM}$ NBT with $5 \mathrm{mM}$ sodium formate $(\mathrm{pH}=5.6)$ to $7.5 \mathrm{kGy}$ and $15 \mathrm{kGy}$ in the temperature range of $5-25{ }^{\circ} \mathrm{C}$. A set of three samples was used for each temperature. The variations in absorbance were normalized with respect to that at an irradiation temperature of $5{ }^{\circ} \mathrm{C}$ (see Fig. $5(\mathrm{a}$ and $\mathrm{b}$ ). The results show that dosimeters depend on irradiation temperature so that, the response of the solutions has to be corrected under actual processing conditions [2]. This result is in agreement with previous work by [8].

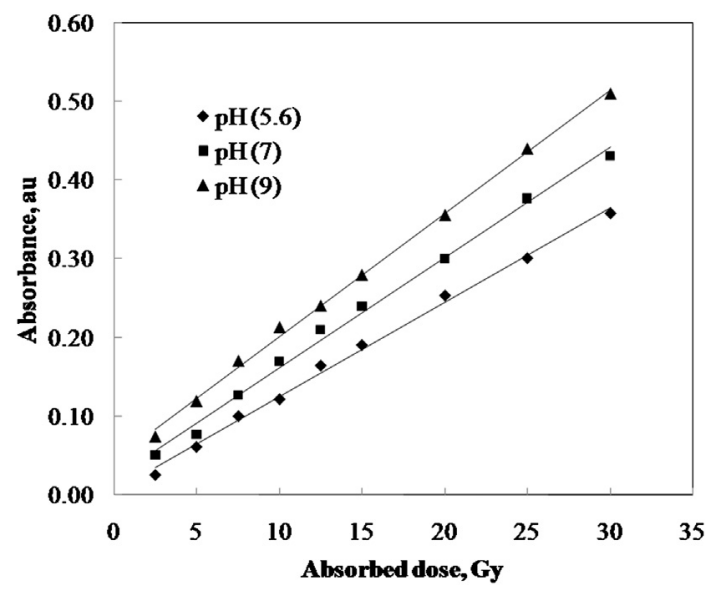

Figure 4 Absorbance of $5 \mathrm{mM} \mathrm{NBT}$ and $5 \mathrm{mM}$ sodium formate solution dosimeters with different $\mathrm{pH}$ values as a function of dose. 

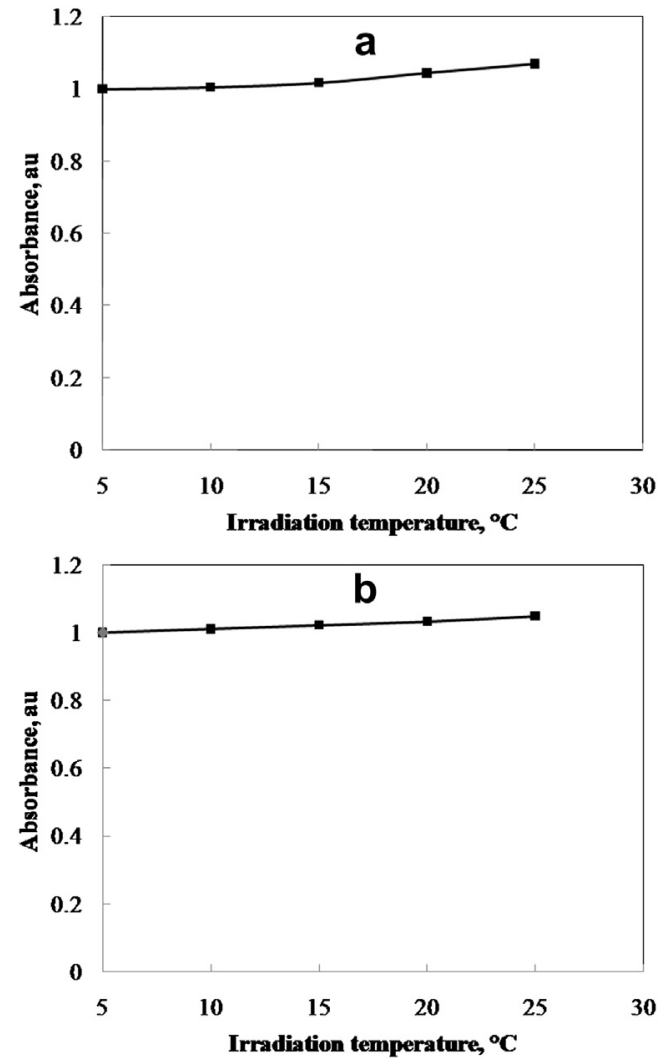

Figure 5 Absorbance of $5 \mathrm{mM} \mathrm{NBT}$ with $5 \mathrm{mM}$ sodium formate $(\mathrm{pH}=5.6)$ solution dosimeters normalized with respect to that at irradiation temperature for (a) $7.5 \mathrm{~Gy}$ and (b) $15 \mathrm{~Gy}$.

\section{Stability of NBT solution dosimeter after irradiation}

The stability of NBT solution dosimeters was investigated by measuring the absorbance of NBT solution containing $5 \mathrm{mM}$ NBT $(\mathrm{pH}=5.6), 5 \mathrm{mM}$ NBT with $5 \mathrm{mM}$ sodium formate $(\mathrm{pH}=5.6)$ and $5 \mathrm{mM} \mathrm{NBT}$ with $5 \mathrm{mM}$ sodium formate $(\mathrm{pH}=9)$. The samples were irradiated to15 kGy at irradiation temperature of $20 \pm 1{ }^{\circ} \mathrm{C}$ and kept under normal laboratory conditions in the dark. A set of three solutions

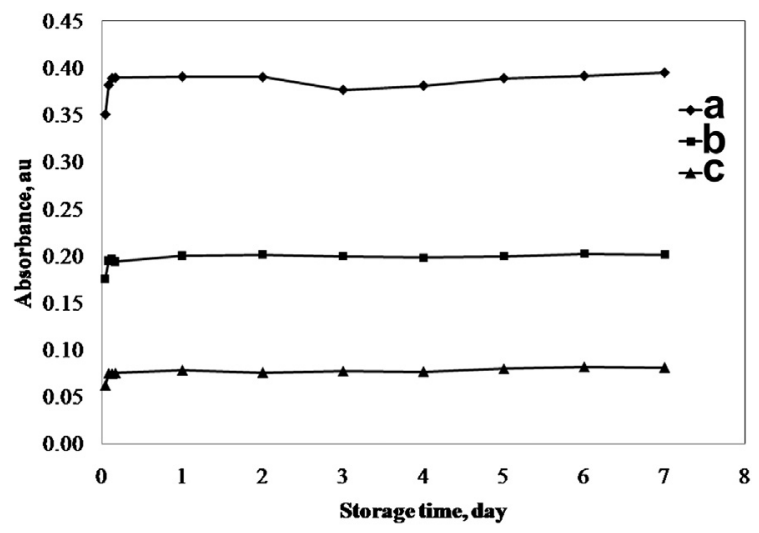

Figure 6 Absorbance of $5 \mathrm{mM} \mathrm{NBT}$ solution dosimeters irradiated to $15 \mathrm{~Gy}$ as a function of storage time, (a) without sodium format (b) with $5 \mathrm{mM}$ sodium formate $(\mathrm{pH}=5.6)$ and (c) with $5 \mathrm{mM}$ sodium formate $(\mathrm{pH}=9)$.

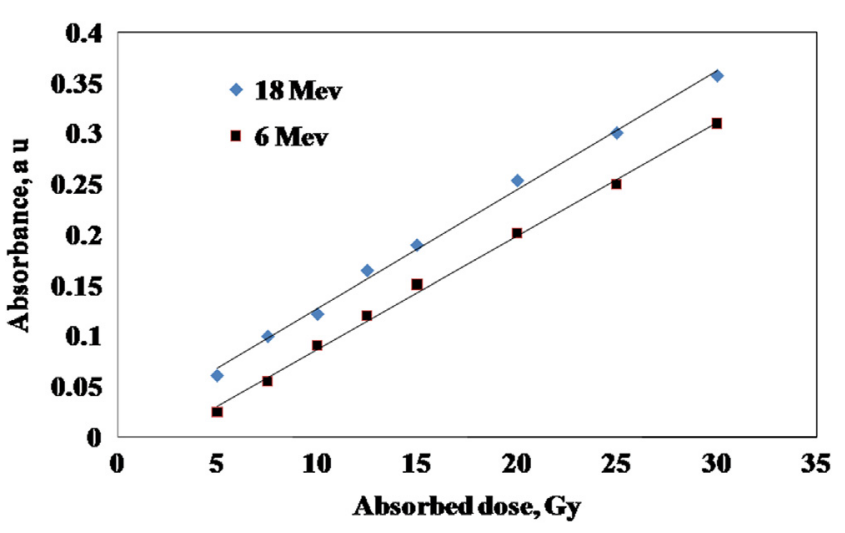

Figure 7 Absorbance of $5 \mathrm{mM} \mathrm{NBT}$ with $5 \mathrm{mM}$ sodium formate $(\mathrm{pH}=5.6)$ solution dosimeters irradiated with 4 and $18 \mathrm{MV}$ $\mathrm{X}$-ray beam.

was used for each absorbed dose. The stability of irradiated solution changes reasonably (less than $\pm 14 \% ; 1 \sigma$ ) up to $2 \mathrm{~h}$, after that the results show no change (less than $\pm 4 \% ; 1 \sigma$ ) in the absorbance of the NBT dosimeters up to 7 days (see Fig. 6). This result is in agreement with previous work by $[4,12,13]$.

\section{Effect of X-ray energy}

The effect of X-ray energy on the response of NBT solution dosimeters was investigated by using 4 and $18 \mathrm{MV}$ X-ray beam (Varian Medical Systems Inc.). $5 \mathrm{mM}$ NBT with $5 \mathrm{mM}$ sodium formate $(\mathrm{pH}=5.6)$ solutions dosimeters were irradiated with different doses at $15 \mathrm{~cm}$ depth, $100 \mathrm{~cm}$ (SSD) set-up and $10 \times 10 \mathrm{~cm}^{2}$ field size. The results show that dosimeters depend on irradiation temperature (see Fig. 7) so that, the response of the solutions has to be corrected under actual processing conditions [2]. This result is in agreement with previous work by [5].

\section{Conclusions}

NBT solution dosimeters were prepared with various concentrations of NBT dye from 1 to $5 \mathrm{mM}$. Systematic evaluation of dosimetric properties for the dosimeters was investigated and found useful for medical dosimetry. The absorbance increases with absorbed dose in the dose range up to $30 \mathrm{~Gy}$. The dose sensitivity increases strongly with increase of concentration of NBT dye. The dose response of NBT dosimeters increases remarkably by addition of various concentrations of sodium formate. It becomes more remarkable with increasing $\mathrm{pH}$ value of NBT sodium formate dosimeters. The sensitivity of the solution increased fairly with increase of irradiation temperature, therefore, the response of the solution has to be corrected under actual processing conditions. The stability of solution dosimeters after irradiation was very high up to 30 days.

\section{Acknowledgment}

The authors would like to acknowledge the support of King Abdulaziz City for Science and Technology (KACST) in funding this project. The assistance of Mr. Fareed Hussien 
Mahyoub of Biomedical Physics Department, King Faisal Specialist Hospital and Research Center (KFSH\&RC) is greatly appreciated.

\section{References}

[1] Appleby Alan. Radio-chromic imaging methods, USA patent no. 569342; 2003.

[2] ASTM. Standard guide for performance characterization of dosimeters and dosimetry systems for use in radiation processing. ASTM E2701-09; 2009.

[3] Auclair C, Voisin E. Nitro blue tetrazolium reduction. In: Greenwald RA, editor. CRC handbook of methods for oxygen radical research. CRC Press Inc, Boca Raton; 1985.

[4] Basfar AA, Rabaeh KA, Moussa AA, Msalam RI. Dosimetry characterization of nitro-blue tetrazolium polyvinyl butyral films for radiation processing. Radiat Phys Chem 2011;80:763.

[5] Butson MJ, Yu PKN, Cheung T, Metcalfe P. Radiochromic film for medical radiation dosimetry. Mater Sci Eng R 2003;41:61-120.

[6] Davies JB, Baldock C. Sensitivity and stability of the Fricke-gelatin-xylenol orange gel dosimeter. Radiat Phys Chem 2008;77:696.

[7] Emi-Reynolds G, Kovacs A, Fletcher JJ. The response characteristics of tetrazolium violet solutions to gamma irradiation. Radiat Phys Chem 2007b;76:1515.

[8] Farah K, Kuntz F, Kadri O, Ghedira L. Investigation of the effect of some irradiation parameters on the response of various types of dosimeters to electron irradiation. Radiat Phys Chem 2004;71:337.
[9] Healy BJ. Effects of saccharide additives on response of ferrous-agarose-xylenol orange radiotherapy gel dosimeters. Med Phys 2003;30:2282.

[10] Keall P, Baldock C. A theoretical study of the radiological properties and water equivalence of Fricke and polymer gels used for radiation dosimetry. Aust Phys Eng Sci Med 1999;22:85.

[11] Kovács A, Wojnárovits L, Baranyai M, Moussa A, Othman I, Mclaughlin WL. Aqueous-ethanol nitro blue tetrazoium solutions for high dose dosimetry". Radiat Phys Chem 1999; 55:799.

[12] Kovács A, Wojnárovits L, Mclaughlin WL, Ebraheem Eid SE, Miller A. Radiation-chemical reaction of 2,3,5-triphenyltetrazolium chloride in liquid and solid state. Radiat Phys Chem 1996;47:483.

[13] Moussa A, Baranyai M, Wojnarovits L, Kovacs A, McLaughlin WL. Dosimetry characteristics of the nitro blue tetrazolium polyvinylalcohol film for high dose applications. Radiat Phys Chem 2003;68:1011.

[14] Rabaeh KA, Basfar AA, Moussa AA. Enhancement in sensitivity of nitro blue tetrazolium polyvinyl alcohol film dosimeters by sodium formate and Triton X-100. Radiat Phys Chem 2012;81: 479-83.

[15] Sadeghi Ali, Chaychian Mahnaz, Al-Sheikhly Mohamad, McLaughlin WL. Radiation-induced reduction of ditetrazolium salt in aqueous solutions. Radiat Phys Chem 2004;64:13.

[16] Soares CG. Radiochromic film dosimetry. Radiat Measurements 2007;41:100.

[17] Von Sonntag C. The chemical basis of radiation biology, Taylor and Francis, London; 1987. 